\title{
Evaluation of Clinical Risk Index for Babies to Predict Mortality and Morbidity in Neonates Admitted to Neonatal Intensive Care Unit
}

\author{
Alireza Jashni Motlagh ${ }^{1 *}$, Reyhane Asgary ${ }^{2}$, Kourosh Kabir ${ }^{3}$
}

\begin{abstract}
${ }^{1}$ Pediatrician and Neonatologist Assistant Professor of Pediatrics \& Amp; Neonatology, Alborz University of Medical Sciences, Karaj, IRAN ${ }^{2}$ General Practitioner, Tehran Medical Sciences Branch, Islamic Azad University, Tehran, IRAN

${ }^{3}$ Associate Professor of Biostatic, Social Determinants of Health Research Center, Alborz University of Medical Sciences, Karaj, IRAN *Corresponding Author: aj_motlagh@yahoo.com
\end{abstract}

Citation: Motlagh AJ, Asgary R, Kabir K. Evaluation of Clinical Risk Index for Babies to Predict Mortality and Morbidity in Neonates Admitted to Neonatal Intensive Care Unit. Electron J Gen Med. 2020;17(5):em232. https://doi.org/10.29333/ejgm/7902

\section{ARTICLE INFO}

Received: 11 Oct. 2019

Accepted: 3 Feb. 2020

\section{ABSTRACT}

Background: Premature birth, low birth weight, and congenital malformations are the main causes of neonata mortality. The current study aimed at evaluating the predictive index of mortality and short-term morbidity of premature neonates in a hospital in karaj, Iran

Methods: The present cross sectional study was conducted on 145 neonates admitted to the neonatal intensive care unit of (NICU) at Bahonar Hospital in karaj, Iran from 2014 to 2017. Neonates were selected by available sampling method and data were collected using their records; the mortality rate was calculated using the CRIB (clinical risk index for babies) checklist. Data were analyzed statistically.

Results: The current study results indicated the high efficiency of both CRIB and CRIBII variables in predicting neonatal mortality $(P=0.000)$. The mean CRIB and CRIBII scores were respectively 9.24 and 9.04 in infants died during the study.

Discussion: The CRIB score had a higher value in predicting mortality compared to that of CRIBII. CRIB score had a significant correlation with retinopathy of prematurity $(R O P)(P=0.01)$ and respiratory distress syndrome (RDS) $(P=0.011)$, but no significant relationship was found between CRIBII and the studied complications. There was a significant correlation between CRIB and CRIBII scores $>8$, and neural tube defect $(P=0.000)$. The predictive value of the CRIB score for neural tube defect was higher than that of the CRIBII.

Conclusion: The results of the current study showed that CRIB and CRIBII can be utilized to predict mortality and neural tube defect in preterm infants and CRIB score can be used to predict ROP and RDS.

Keywords: neonates, mortality, morbidity

\section{INTRODUCTION}

The risk of neonatal death is high during labor, so that the highest infant mortality rate occurs within the first 24 hours of life (1,2). Prematurity, low birth weight and congenital malformations are the most important cause of neonatal mortality (3).

According to the World Health Organization (WHO), about 8 million infants annually die within first 12 months of life. Infant mortality is an important issue in developing countries and has a high economic and social burden (4). Although infant mortality rate, like some other development indicators, has a declining trend, many infants still die worldwide. According to WHO report, 5.9 million children under five died in 2015; i e, 16,000 deaths per day; $45 \%$ of them were infants (19.2 deaths per 1000 live births), 454,000 cases only occurred in the Eastern Mediterranean region (EMR) $(5,6)$.

Iran's share, as a country in EMR, is 13,000 infant deaths with an average mortality rate of 9.5 (6-14.4) per 1000 live births, compared to 16 per 1000 live births in 2009 (7).
Low birth weight and premature infants face more challenges compared to full-term ones, so that their mortality rate is 4.5 times, and morbidity and disease rate 3.5 times higher that term infants. The survival rate of such infants depends on different factors including birth weight, gestational age, congenital malformations, and quality of neonatal care (8$11)$.

In recent years, with the advancements and improvements in neonatal care, the survival chance of such infants increased, but consequently, the risk of complications including retinopathy of prematurity (ROP), hearing problems, neural tube defects, and bacteremia increased (12). Given the importance of these diseases and the necessity of their prevention, an instrument to identify the critically ill infants on admission in order to help the treatment team is highly required (13-15). More than a decade ago, "clinical risk scoring systems for infants"- $i$ e, CRIB and CRIBII were utilized to assess the health status and predict mortality in infants admitted to neonatal intensive care units (NICUs).

The CRIB (clinical risk index for babies) is a scoring system consisting of six variables including birth weight, gestational 
Table 1. The Correlation between CRIB and Mortality Rate in Infants Admitted to the Neonatal Intensive Care Unit

\begin{tabular}{cccc}
\hline Mortality and morbidity & status & Mean \pm SD (CRIBI) & Frequency (percent) \\
\hline \multirow{2}{*}{ Death } & yes & $4.2 \pm 2.5$ & $116(80 \%)$ \\
\cline { 2 - 4 } & no & $9.2 \pm 3.2$ & $29(20 \%)$ \\
\cline { 2 - 4 } Neural tube defect & yes & $8.6 \pm 1.4$ & $126(87 \%)$ \\
\hline \multirow{2}{*}{ Retinopathy of prematurity } & no & $4.4 \pm 1.2$ & $19(13 \%)$ \\
\cline { 2 - 4 } & yes & 8.000 & $85(58 \%)$ \\
\hline
\end{tabular}

*Mann Whitney test

age, congenital malformations, minimum and maximum oxygen consumption, and maximal base excess used within the first 12 hours of hospitalization (16).

The CRIBII, the revised version on CRIB, consists of five variables of birth weight based on gestational age, congenital abnormality, gender, body temperature on admission, and maximal base excess. Some researchers believe that the CRIBII has a higher value in predicting mortality rate of premature neonates with birth weight less than $1500 \mathrm{~g}$ (17) compared to birth weight and gestational age variables (18), and helps predict hospital mortality rate among premature infants (19).

CRIB is an important index in predicting the severity of disease and even infant's death. An integer is assigned to each variable of both indices based on predefined classifications and according to infant's health status; the sum of integers yields CRIB and CRIBII scores. A higher score in each of the two indices indicates a more severe disease and worse prognosis (20).

Considering the importance of these indices and since no research from Iran investigated the efficacy of CRIB and CRIBII in premature neonatal morbidity so far, the current study aimed at comparing these indices in predicting mortality and short-term morbidity in preterm infants admitted to NICU at Bahonar Hospital in Karaj, Iran from 2014 to 2017 (21,22).

\section{METHOD}

The current cross sectional, retrospective study was conducted on 145 neonates admitted to NICU at Bahonar Hospital in karaj from 2014 to 2017.

\section{Participant's Characteristics}

All neonates with gestational age of 23-37 weeks admitted to NICU within the first 12 hours of life from 2014 to 2017 were enrolled in the current study.

\section{Exclusion Criteria}

1) Infants weighing less than $500 \mathrm{~g}$

2) Admission after the first 12 hours of life

3) Death during the first 12 hours of life

4) Infants with inevitably lethal congenital malformations, such as trisomy 13 and 18

\section{DATA COLLECTION INSTRUMENTS}

Demographic and required data were extracted from the neonates' records in the NICU at Imam Ali Hospital. Then the CRIB and CRIBII scores were calculated. Infants' gestational age was calculated based on last menstrual period and ultrasound of the first trimester of pregnancy using maternal records and in case of inconsistency, gestational age was determined according to pediatricians' estimation. Data were evaluated using records of neonates and the rate of risk was assessed based on CRIB and CRIBII of infant's disease progression including short-term morbidity such as Retinopathy of prematurity (ROP), neural tube defects, hearing problems, bacteremia, and respiratory distress syndrome (RDS) until death.

\section{DATA ANALYSIS}

The collected data were analyzed with SPSS version 24 software. Frequency and frequency percentage were used to express qualitative variables and mean and standard deviation for quantitative variables. Shapiro test was used to assess the distribution of CRIB.

The Mann-Whitney test was used to compare CRIB and CRIBII in predicting neonatal mortality, ROP, hearing problems, neural tube defects, and RDS.

Spearman correlation test and ANOVA were used to determine the correlation of CRIB and CRIBII with blood acidosis and blood glucose, respectively and determine the correlation of CRIB and CRIBII with heart problems rate.

\section{RESULTS}

A total of 145 infants were investigated in the current study, of them $75(51.7 \%)$ were female and $70(48.3 \%)$ male. The weight of subjects ranged 500 to $3800 \mathrm{~g}$ (mean: $1913.1 \pm 57.67)$. The gestational age of the subjects ranged 24 to 37 weeks (mean: $32.4 \pm 3.01$ ). Only $4.3 \%$ of the subjects had congenital malformations and the body temperature of most infants (56.6\%) ranged $36.2^{\circ} \mathrm{C}$ to $37.3^{\circ} \mathrm{C}$.

Most infants were in the desirable health status based on the oxygen consumption percentage $\left(40.7 \%\right.$ had $\left.\mathrm{sO}_{2}>70 \%\right)$; maximal base excess (based on the results of arterial blood gas analysis) in $67.2 \%$ of the neonates ranged -10 to -2 .

The mean CRIBI score of died infants was significantly higher than that of others (4.22 vs. 9.24). Besides, $89.7 \%$ of died infants had a CRIBI score of $>5(P=0.000)$ (Table 1$)$.

According to the results, there was a relationship between CRIB and the rate of ROP; in other words, CRIB score of patients with ROP was significantly higher than that of others $(P=0.01)$.

There was a significant relationship between CRIB and neural tube defects; so that the CRIB score of neonates with neural tube defects was significantly higher than that of others (8.68 vs. $4.43 ; \mathrm{P}=0.000$ ).

CRIB score was also associated with RDS in premature infants admitted to NICU; so that the mean score of CRIB was 5.63 in infants with RDS and 3.12 in others $(P=0.011)$ (Table 2$)$. 
Table 2. Relationship between CRBII Score, and Blood Acidosis and Blood Glucose in Infants

\begin{tabular}{ccccc}
\hline CRIB Score & $\mathbf{<}$ & $\mathbf{5 - 1 0}$ & $\mathbf{> 1 0}$ & P-value \\
\hline Mean blood acidosis & 7.32 & 7.27 & 7.21 & $<0.001$ \\
\hline Mean blood glucose & 127.2 & 186.87 & 315.64 & $<0.001$ \\
\hline
\end{tabular}

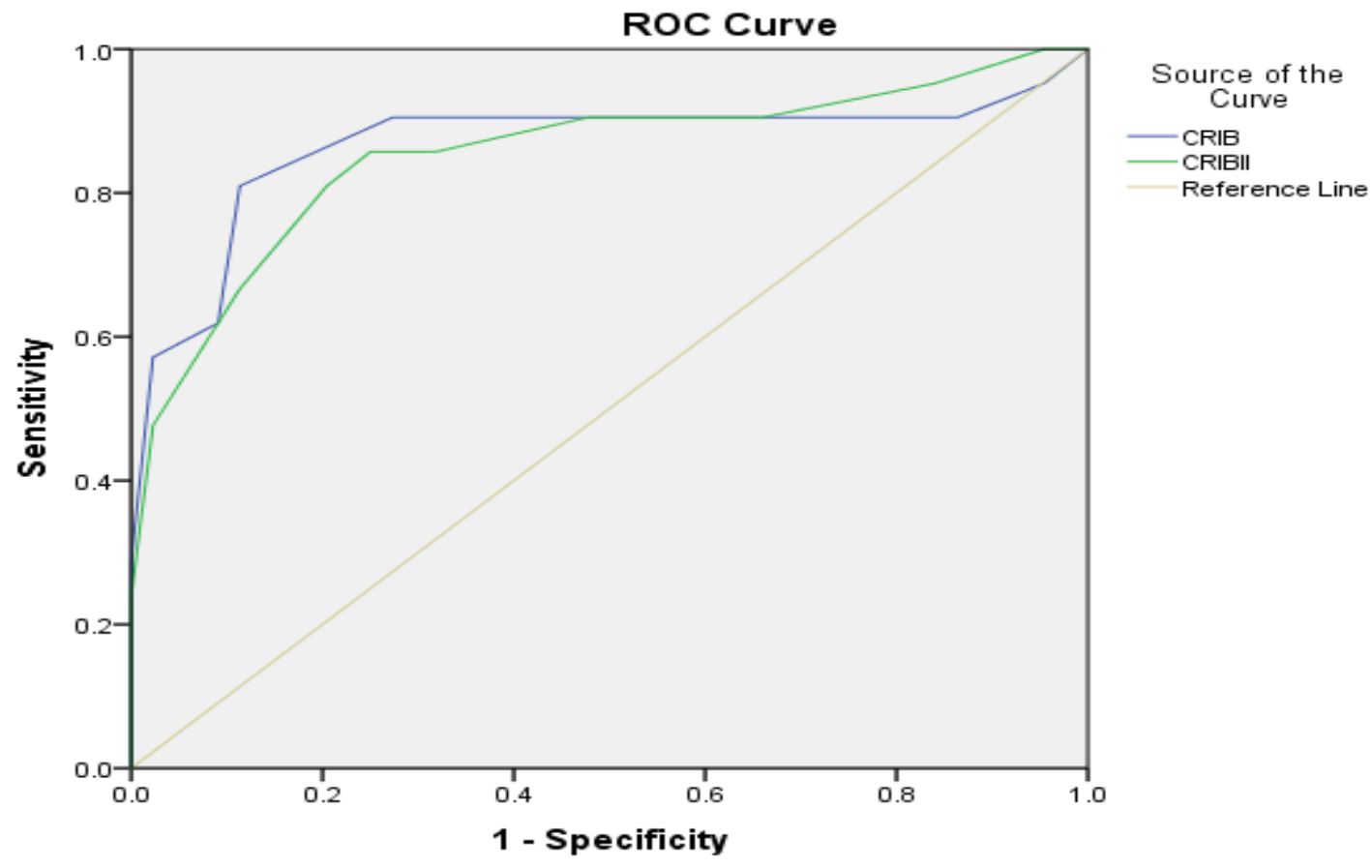

Diagonal segments are produced by ties.

Figure 1. ROC curve of CRIB and CRIBII scores in predicting infants' mortality

The AUC value for CRIB was 0.904 , indicating the efficiency of this variable for predicting RDS. The optimal cutoff point for CRIB was 8.5 with $68.3 \%$ sensitivity and $100 \%$ specificity.

$$
\mathrm{AUC}_{\mathrm{CRIB}}=904 ; C I: 0.797-1.000
$$

A relatively significant and inverse relationship was found between arterial blood acidosis and CRIB in preterm infants admitted to NICU $(P=0.000, R=-0.04)$.

Mean blood glucose of neonates had a significant correlation with CRIB score $(R=0.32, P=0.00)$, but the current study results showed no significant relationship between $C R I B$ score and the rate of hearing problems in preterm infants $(P=$ 0.671).

The results also showed no significant correlation between CRIB score and bacteremia based on positive CRP test result in preterm infants admitted to NICU $(P=0.513)$.

There was no significant relationship between CRIB score and heart problems $(P-=0.091)$.

In addition, $14.3 \%$ of died infants had a CRIBII score of $\leq 4$, which ranged 5 to 8 for $19 \%$ of died infants. Also, $66.7 \%$ of all deaths belonged to infants with CRIBII score of $\geq 9$.

There was a significant relationship between CRIBII score and neural tube defects in preterm infants, so that the CRIBII score of neonates with neural tube defects was significantly higher than that of others ( 8.00 vs. $4.92 ; \mathrm{P}=0.002$ ).

Spearman correlation test showed a poor and adverse relationship between $\mathrm{CRIBII}$ score and premature neonates arterial blood acidosis $(P=0.05, R=-0.253)$.
The correlation of blood acidosis and blood glucose with CRIBII score of neonates is shown in (Table 2).

There was a significant and positive correlation between higher CRBI scores and increased blood glucose in infants. However, the correlation of CRIB score with blood acidosis was inverse and significant $(P<0.001)$.

According to Figure 1, the ROC curve was drawn to compare CRIB and CRIBII in predicting mortality rate of premature neonates. The results showed that the AUC of CRIB was slightly higher than that of CRIBII, but the results indicated a high efficiency of both variables in predicting infants' mortality. However, it can be said that the CRIB score has a higher predictive value than the CRIBII. The optimal cutoff point for CRIB was 7.5 with $90 \%$ sensitivity and $72.7 \%$ specificity and for CRIBII was 6.5 with $85.7 \%$ sensitivity and $75 \%$ specificity.

$$
\begin{aligned}
& A U C_{C R I B}=.866 ; C I: 0.746-0.987 \\
& A U C_{C R I B}=.853 ; C I: 0.741-0.966
\end{aligned}
$$

According to Figure 2, the AUC of CRIB was larger than that of CRIBII for predicting neural tube defects. Therefore, it can be said that the CRIB score had a higher value than that of CRIBII in predicting neural tube defects. The optimal cutoff point for CRIB was 5.5 with $86.7 \%$ sensitivity and $63.2 \%$ specificity and 7.5 for CRIBII with $73.3 \%$ sensitivity and $78.9 \%$ specificity.

$$
\begin{aligned}
& A U C_{C R I B}=.759 ; C I: 0.595-0.923 \\
& A U C_{C R I B}=.774 ; C I: 0.607-0.940
\end{aligned}
$$




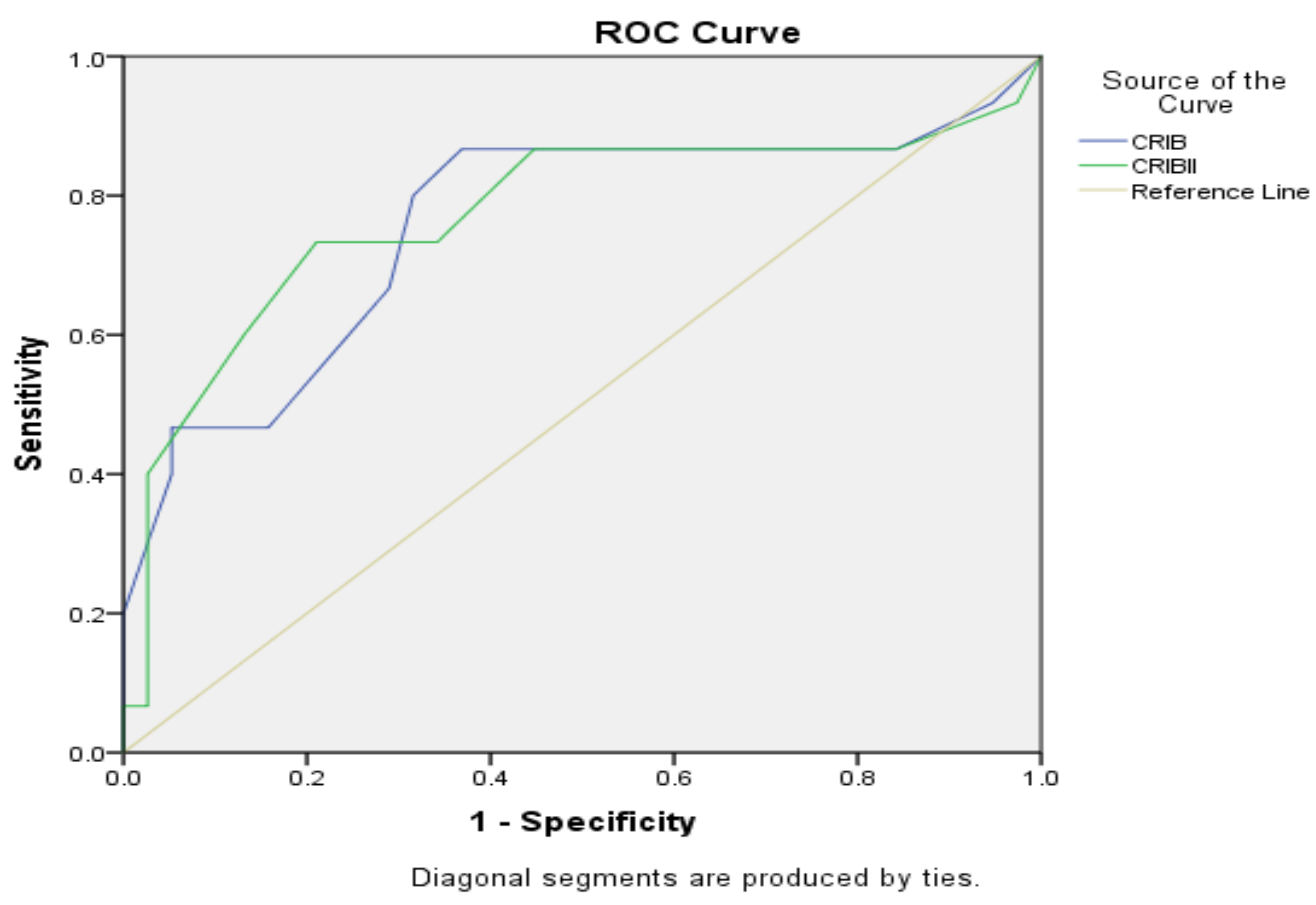

Figure 2. ROC curve for neural tube defect variable

\section{DISCUSSION}

The results of the study showed that CRIB and CRIBII had high efficacy in predicting neonatal mortality $(P=0.000)$. CRIB also had a more value in predicting mortality than CRIBII.

In a study by Marto et al, the correlation of CRIBII score with neonatal mortality rate was higher than that of CRIB (23). A study by Ezzedine et al reported the mean CRIBII score of 9.9, indicating high value of CRIBII in predicting neonatal mortality rate (24-27). The higher the CRIB and CRIBII scores, the higher the risk of morality.

In the study by de Brito et al., the CRIB was also reported as a more accurate index in predicting neonatal mortality than birth weight and gestational age. They considered the CRIB score of $\geq 9$ on average as high risk. In the current study, CRIB was a good factor for predicting neonatal mortality rate (28).

Bazrafcan and Amin, evaluated the value of CRIB, SNAP, and SNAP_PE in determining the disease severity and predicting mortality in neonates admitted to NICU (29). In their cross sectional study, 60 out of 200 studied neonates died $(30 \%)$, the median CRIB was higher in died patients. Consequently, the CRIB could be a reliable method to predict mortality and determine disease severity in neonates; they also recommended the utilization of CRIB even for patients who admitted to NICU (30-33).

In the reviewed studies, in agreement with the current study, CRIB and CRIBII had a good value in predicting neonatal mortality (34-36).

The current study findings showed a significant correlation between CRIB score and incidence of ROP $(P=0.01)$, but no correlation was found between CRIBII score and ROP. The lack of correlation between CRIBII score and ROP may be due to that CRIBII only covers premature infants with gestational age less than 32 weeks; the point that affects the obtained result (37).

Pirmoradi et al., in a study in Florida evaluated the association of race, gender, and CRIB score in predicting severe
ROP, which of 299 patients, 35 (11.7\%) cases developed ROP that required surgical intervention. Likewise, the study findings revealed that these infants had a high CRIB score (38).

Ahmadpour et al. also examined the correlation of ROP with CRIB score. Of the 256 studied neonates, 180 (70\%) had retinopathy in some degrees, of which 56 (31.11\%) required treatment, although the relationship between CRIB score and severity of retinopathy was insignificant $(P=0.152)$; hence, the CRIB cannot predict the severity, progression, or remission of retinopathy (39-42).

In addition, in the present study, a significant correlation was found between CRIB and CRIBII, and neural tube defect, with higher predictive value of the CRIB than CRIBII $(43,44)$.

Consistent with the results of the study by de CourcyWheeler et al., the CRIB score can significantly predict neural tube defects $(P<0.0001)$, and the risk of Neural tube defects increases from $5 \%$ in the CRIB scores of 0 to 5 to $28 \%$ in the CRIB score of $>11(45,46)$.

In the study by Lodha et al, a significant correlation was reported between CRIBII score and long-term neurodevelopmental outcomes (47).

But according to the results of the present study, there was no significant correlation between CRIB and CRIBII scores and rate of hearing problems, bacteremia, and heart problems. Lack of correlation between CRIBII score and the studied morbidity including hearing problems, RDS, bacteremia, and heart problems might be due to small sample size of CRIBII scores (48).

In the study of Rastogi et al., the ROC curve for mortality was 0.9 based on CRIB-II, which was inconsistent with that of the current study. Researchers have attributed such discrepancies to sample size error and increased percentage error in small sample sizes (49) and recommended further studies in the same field.

Finally, Primary care and practice have always generated a great deal of innovation in care, professionals are continuously 
reviewing their practice and ways in which to change procedures to enhance patient care. since neonatal mortality rate is still high and the quality of intensive care can significantly improve neonatal outcomes, utilization of CRIB and CRIBII is advantageous. Although the efficacy of the studied indices was shown in the present and some other studies, further investigations are still recommended to address the contradictions regarding the predictive value of CRIB and CRIBII for some neonatal complications.

\section{CONCLUSION}

The results of the study showed that CRIB and CRIBII can be utilized to predict mortality and neural tube defects in preterm infants. The CRIB score can also be effective in predicting complications such as ROP and RDS in preterm infants. Therefore, it is recommended to utilize CRIB and CRIBII routinely to predict mortality and short-term morbidity in preterm infants.

\section{ACKNOWLEDGEMENTS}

The authors hereby acknowledge their gratitude to the Clinical Development and Research Unit of Bahonar and kamali Hospital for material and spiritual support of the study.

\section{Disclosure Statement}

The authors report no conflict of interest.

\section{REFERENCES}

1. Kliegman RM, Behrman RE, Jenson HB, Stanton BM. Nelson textbook of pediatrics e-book: Elsevier Health Sciences; 2007.

2. Hartman M, Cheifetz IM. Pediatric emergencies and resuscitation. Nelson textbook of pediatrics. 2011;20:489506. https://doi.org/10.1016/B978-1-4377-0755-7.00062-2

3. Almasi-Hashiani A, Sepidarkish M, Vesali S, Omani Samani R. The Correlation of Human Development Index on Fertility and Mortality Rate: a Global Ecological Study. International Journal of Pediatrics. 2016;4(12):4071-80.

4. Salarilak S, Khalkhali H, Entezarmahdi R, Pakdel F, Faroukheslamloo H. Association between the socioeconomic indicators and infant mortality rate (IMR) in Iran. Iranian Journal of Public Health. 2009:21-8.

5. Ogawa M, Matsuda Y, Kanda E, Konno J, Mitani M, Makino Y, et al. Survival rate of extremely low birth weight infants and its risk factors: case-control study in Japan. ISRN obstetrics and gynecology. 2013;2013. https://doi.org/10.1155/ 2013/873563 PMid:24371528 PMCid:PMC3858981

6. Gouyon J-B, lacobelli S, Ferdynus C, Bonsante F, editors. Neonatal problems of late and moderate preterm infants. Seminars in Fetal and Neonatal Medicine; 2012: Elsevier. https://doi.org/10.1016/j.siny.2012.01.015 PMid:22349153

7. Ahmadpour-kacho M, Zahed Pasha Y, Rasoulinejad SA, Hajiahmadi M, Pourdad P. Correlation between retinopathy of prematurity and clinical risk index for babies score. Tehran University Medical Journal TUMS Publications. 2014;72(6):404-11.

8. Babaei $\mathrm{H}$, Jafrasteh $\mathrm{A}$. The evaluation of CRIB II scoring system in predicting mortality in preterm newborns. 2015.
9. Vasudevan A, Malhotra A, Lodha R, Kabra S. Profile of neonates admitted in pediatric ICU and validation of Score for Neonatal Acute Physiology (SNAP). Indian Pediatrics. 2006;43(4):344.

10. Ghaffari Saravi V, Khani S, Kosarian M. Predictive value of SNAP-PE, SNAP, CRIB indices for prediction of disease severity and determination of death in infants admitted to NICU. Journal of Mazandaran University of Medical Sciences. 2009;19(73):1-9.

11. Marete IK, Wasunna A, Otieno P. Clinical risk index for babies (CRIB) II score as a predictor of neonatal mortality among low birth weight babies at Kenyatta National Hospital. East African medical journal. 2011;88(1):18-23.

12. Ezz-Eldin ZM, Hamid TAA, Youssef MRL, Nabil HE-D. Clinical risk index for babies (CRIB II) scoring system in prediction of mortality in premature babies. Journal of clinical and diagnostic research: JCDR. 2015;9(6):SC08.

13. de Brito ASJ, Matsuo T, Gonzalez MRC, de Carvalho ABR, Ferrari LS. CRIB score, birth weight and gestational age in neonatal mortality risk evaluation. Revista de saude publica. 2003;37(5):597-602. https://doi.org/10.1590/ S0034-89102003000500008 PMid:14569335

14. Saravi VG, Khani S, Kosarian M. Predictive value of SNAP$\mathrm{PE}, \mathrm{SNAP}, \mathrm{CRIB}$ indices for prediction of disease severity and determination of death in infants admitted to NICU. Journal of Mazandaran University of Medical Sciences (JMUMS). 2009;19(73).

15. Yang MB, Donovan EF, Wagge JR. Race, gender, and clinical risk index for babies (CRIB) score as predictors of severe retinopathy of prematurity. Journal of American Association for Pediatric Ophthalmology and Strabismus. 2006;10(3):253-61. https://doi.org/10.1016/j.jaapos.2006. 01.004 PMid: 16814180

16. de Courcy-Wheeler R, Wolfe C, Fitzgerald A, Spencer M, Goodman J, Gamsu HR. Use of the CRIB (clinical risk index for babies) score in prediction of neonatal mortality and morbidity. Archives of Disease in Childhood-Fetal and Neonatal Edition. 1995;73(1):F32-F6. https://doi.org/ 10.1136/fn.73.1.F32 PMid:7552593 PMCid:PMC2528363

17. Lodha A, Sauve R, Chen S, Tang S, Christianson H. Clinical Risk Index for Babies score for the prediction of neurodevelopmental outcomes at 3 years of age in infants of very low birthweight. Developmental Medicine \& Child Neurology. 2009;51(11):895-900. https://doi.org/10.1111/ j.1469-8749.2009.03284.x PMid:19416333

18. Rastogi PK, Sreenivas V, Kumar N. Validation of CRIB II for prediction of mortality in premature babies. Indian pediatrics. 2010;47(2):145-7. https://doi.org/10.1007/ s13312-010-0022-5 PMid:19578231

19. Pouyan P, Akbari M, Rahimzadeh M, Jamshidimanesh M, Esmaelzadeh S. Effect of Interpersonal Psychotherapy Oriented Child Birth Education on Stress and Role Adaptation in Mothers with Premature Birth: A Randomized Clinical Trial. iranian journal of psychiatry \& behavioral sciences. 2019;13(1):e86645. https://doi.org/10.5812/ ijpbs. 86645

20. Basu S, Rathore P, Bhatia B. Predictors of mortality in very low birth weight neonates in India. Singapore medical journal. 2008;49(7):556.

21. Yadollahi P, Khalajinia Z, Khormaei F. Cultural differences in perception of labor pain without considering to painless technique. Journal of Advanced Pharmacy Education \& Research, 2018;8(S2):9-14. 
22. Yadollahi P, Taghizdeh Z, Ebadi A. A comprehensive description of delivery pain using a qualitative approach. Journal of Advanced Pharmacy Education \& Research, 2018;8(S2):59-63.

23. Khorasani Baghini F, Khosravani M, Amiri A. Evaluation of the effect of the provided training in delivery preparation classes on awareness and attitude of pregnant mothers toward delivery type in Razi Hospital of Saravan. Revista Latinoamericana de Hipertension, 2018;13(6):534-7.

24. Khorasani Baghini F, Khosravani M, Amiri A, Evaluation of the effect of the provided training in delivery preparation classes on awareness and attitude of pregnant mothers toward delivery type in Razi Hospital of Saravan, Revista Latinoamericana de Hipertensión. 2018;13(6). Available at: http://saber.ucv.ve/ojs/index.php/rev_lh/article/view/159 49

25. Hashemi SB, Amirfakhraei A, Mosallanezhad M, Amiri A. The effect of education on anxiety and self-efficacy in mothers of 1-3-year-old children under cochlear implant surgery, 2018: a randomized controlled clinical trial, Revista Latinoamericana de Hipertensión. 2019;14(1). Available at: http://saber.ucv.ve/ojs/index.php/rev_lh/article/view/161 70

26. Rakhshan M, Rostami K, Setoodegan E, Eslami J. The relationship between leadership style and time management in senior and middle nursing managers, Revista Latinoamericana de Hipertensión. 2019;14(1). Available at: http://saber.ucv.ve/ojs/index.php/rev_lh/ article/view/16173

27. Rostami K, Sharif F, Zarshenas L, Ebadi A, Farbood A. Design and Psychometrics of Measurement Tool of Health Needs in Patients with Chronic Back Ache, Revista Latinoamericana de Hipertensión. 2018;13(3). Available at: http://www.revhipertension.com/index_sumario_3_2018. html

28. Rostami K, Zadeh SH, Rakhshan M. Chronic pain: a concept analysis. Electronic Journal of General Medicine. 2019;16(2):em130. https://doi.org/10.29333/ejgm/94098

29. Bazrafcan L, Amini M. Using CRISIS model for designing master in medical education at Shiraz University of Medical Sciences, Medical Teacher. 2019. https://doi.org/ 10.1080/0142159X.2018.1562540 PMid:30736706

30. Bazrafcan L, Kojuri J, Amini M. Using SPICES educational strategy for undergraduate curricular reform at Shiraz Medical School, Medical Teacher. 2019. https://doi.org/ 10.1080/0142159X.2019.1582759 PMid:30922163

31. Bazrafkan I, Kalyani MN. Nursing Students' Experiences of Clinical Education: A Qualitative Study. Invest. Educ. Enferm. 2018;36(2):e04. https://doi.org/10.17533/ udea.iee.v36n3a04

32. Jaafari F, Delavari S, Bazrafkan L. Evaluation of the geriatric curriculum implemented at Shiraz University of Medical Sciences, Iran, since 2017: A qualitative study [version 1; peer review: 1 approved with reservations]. F1000Research 2019,8:417. https://doi.org/10.12688/f1000research.160 40.1

33. Eslami J, Baghini FK, Moazamfard M. The Effect of Music on the Stress Severity among the Staff of Surgery Rooms. International Journal of Pharmaceutical Research. 2019;11(2):838-43. Available at: http://ijpronline.com/ ViewArticleDetail.aspx?ID=7339
34. Rezapour-Nasrabad R. Application of Transitional Care Model in Patients with Chronic Heart Disease: A CaseControlled Intervention Study, Revista Latinoamericana de Hipertensión. 2018;13(3). Available at: http://www. revhipertension.com/index_sumario_3_2018.html

35. Rezapour-Nasrabad R. Transitional care model: managing the experience of hospital at home, Electronic Journal of General Medicine, 2018;15(5):em73. https://doi.org/ 10.29333/ejgm/93445

36. Amirfakhraei A, Hedayati M, Pirmoradi M. Coping Styles with psychological pressures in students of Iran University of medical sciences, International Journal of Pharmaceutical Research, January-March 2019;11(1):5347. https://doi.org/10.31838/ijpr/2019.11.01.071

37. Pirmoradi M, Foroghinejad N, Bedmeshki FA. The relationship between job satisfaction and social support for employees with chronic fatigue. Ann Trop Med Public Health 2017;10:1681-5. https://doi.org/10.4103/ ATMPH.ATMPH_582_17

38. Pirmoradi M, Ghayoomi R, Foroghinejad N, Bedmeshki FA. The relationship between stressful life events with chronic fatigue in employees of Ahvaz water and Sewage Company, Annals of Tropical Medicine and Public Health-Special Issue Apr 2018;13:SX735-18. Available at: http://www. atmph-specialissues.org/

39. Pirmoradi MR, Poya FS, Rad MT, Veisy F, Gheitarani B, Davoodi R, Ghahari S. Comparison of Anxiety, Depression and Stress and Emotional Self-Regulation in Normal and Divorced Women. International Journal of Tropical Medicine, 2016;11:159-64. https://doi.org/10.3923/ ijtmed.2016.159.164

40. Bazrafkan L, Yousefy A, Amini M, Yamani N. The journey of thesis supervisors from novice to expert: a grounded theory study. BMC medical education. 2019 Dec;19(1):1-2. https://doi.org/10.1186/s12909-019-1739-z PMid:31438935 PMCid:PMC6704648

41. Bijani M, Ghodsbin F, Javanmardi Fard S, Shirazi F, Sharif F, Tehranineshat $B$, An evaluation of adherence to ethical codes among nurses and nursing students, J Med Ethics Hist Med. 2017 Jul 5;10:6. Available at: https://www.ncbi. nlm.nih.gov/pmc/articles/PMC5746660/

42. Torabizadeh C, Ghodsbin F, Javanmardifard S, Shirazi F, Amirkhani M, Bijani M. The Barriers and Challenges of Applying New Strategies in the Clinical Evaluation of Nursing Students from the Viewpoints of Clinical Teachers, Iran J Nurs Midwifery Res. 2018 Jul-Aug;23(4):305-10. https://doi.org/10.4103/ijnmr.IJNMR_17_17 PMid:30034492 PMCid:PMC6034533

43. Bijani M, Rostami K, Momennasab M, Yektatalab S, Evaluating the Effectiveness of a Continuing Education Program for Prevention of Occupational Exposure to Needle Stick Injuries in Nursing Staff Based on Kirkpatrick's Model, J Natl Med Assoc. 2018 Oct;110(5):459-63. https://doi.org/10.1016/j.jnma.2017.11.002 PMid:30129513

44. Torabizadeh C, Mahnazrakhshan, Zhilafreidooni, Njimehbeyfi, Bijani M. Professional Capability in Nursing, International Journal of Pharmaceutical Research, January-March 2019;11(1):556-66. https://doi.org/ 10.31838/ijpr/2019.11.01.075 
45. Bijani M, Haghshenas A, Ghasemi A. Evaluation of the Effect of Education Based on Health Belief Model on Self-Therapy and Self-medication in Students at Fasa Medical Sciences Dormitories, International Journal of Pharmaceutical Research, Jan-Mar 2019;11(3). https://doi.org/10.31838/ ijpr/2019.11.01.124

46. Bijani M, Khaleghi AA, Hatami M, Najafi H, Haghshenas A. A study of the consistency between hypertension medications prescribed by general practitioners and 2018 ESC/ESH guidelines for the management of hypertension, Revista Latinoamericana de Hipertensión. 2019;14(1). Available at: http://saber.ucv.ve/ojs/index.php/rev_lh/ article/view/16174

47. Bijani M, Tehranineshat B, Torabizadeh C., Nurses', nursing students', and nursing instructors' perceptions of professional values: A comparative study, Nurs Ethics. 2019 May;26(3):870-883. https://doi.org/10.1177/09697330177 27153 PMid:28905676
48. Bijani M, Ghasemi A, Karimi S, Freidooni Z, Beygi N. The Role of Educational Intervention Based on the Health Belief Model in Colorectal Cancer Screening of Teachers in Fasa. Journal of Computational and Theoretical Nanoscience. 2019;16(7):2954-2958(5). https://doi.org/10.1166/jctn.2019 .8201

49. Bijani M, Rostami K, Ghasemi A, Emami M, Fereidouni Z. Investigation of diabetes prevention behaviors among teachers of different level of education based on Pender model in selected educational centers in southwestern Iran, 2019. Revista Latinoamericana de Hipertensión. 2019;14(4):290-4. 